\title{
Commentary
}

DOI 10.1007/s12038-012-9207-5

\section{NR Moudgal - A pioneer in the development of immunocontraceptive approaches}

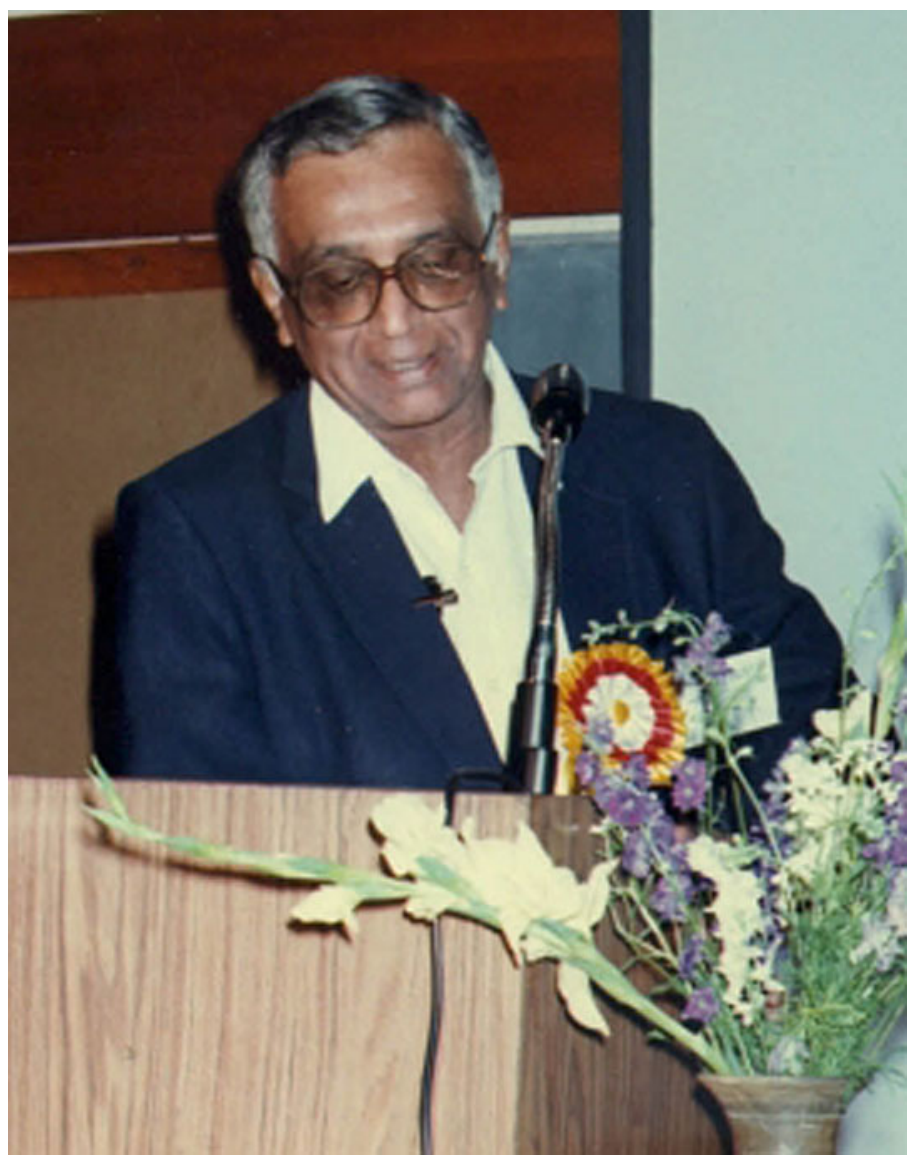

Professor NR Moudgal, an eminent reproductive biologist and endocrinologist and a former professor at the Department of Biochemistry, Indian Institute of Science, Bangalore, and founder editor of the Journal of Biosciences (1979-1983), passed away on 8th May 2011, in Dublin, CA, USA. He was suffering from cancer for a few months before his death.

Nuggehalli Raghuveer Moudgal was born on 4th March 1931 in Mysore, Karnataka, into an upper middle-class family. His father, N Narasimha Moudgal, was Chief Electrical Engineer, Mysore State Electricity Board, and was largely responsible for electrification in the state. His mother, Vaidehi Moudgal, was a homemaker and had tremendous influence on her children, of whom Raghu Moudgal was the youngest of three boys and two girls.

After his BSc degree from University of Mysore, Moudgal moved to Madras for obtaining his MSc by research and worked on the biochemistry of thyroid hormones. He completed his $\mathrm{PhD}$ from Madras University in 1958 under the supervision of Professor PS Sarma, a leading biochemist of India. Moudgal worked as a post-doctoral fellow with Professor Chao Hao Li at University of 
California, Berkeley, CA, USA. Moudgal's work established that pituitary gonadotropins, despite the fact that their major physiological function in reproduction is extensively conserved across the species, are highly immunogenic. This was an observation with far-reaching consequences. Using techniques like quantitative precipitin test, he unequivocally established that antibodies to pituitary protein hormones could be raised in heterologous species. Moudgal continued his association with $\mathrm{Li}$ and Papkoff till the end of his career. Before his return to India, Moudgal was appointed Welcome Research Fellow in the laboratory of Rodney R Porter (Nobel laureate) at St Mary's Hospital Medical School, London (1961-1962) and was working on cellulose as a carrier for immobilization of antibodies. Moudgal's work was greatly influenced by his experience in these two laboratories. He returned to India to work as a CSIR Pool Officer at the All India Institute of Medical Sciences, New Delhi. He joined the Department of Biochemistry, Indian Institute of Science, Bangalore, in 1963 as a Ford Foundation Fellow and later joined the faculty as an Assistant Professor. He rose to the position of Professor and also served as Chairman of the Department of Biochemistry and Dean of the Science Faculty. He retired from the Institute in 1993. Moudgal began his independent career with the help of a generous grant from Ford Foundation, which helped him establish a flourishing school of reproductive biology.

He started work on urinary gonadotropins from macaques, which led to the discovery of an inhibitor of follicle stimulating hormone (FSH). The inhibitor turned out to be a sialidase from the monkey kidney. Primates are known to biosynthesize $N$-acetyl neuraminic acid (NANA) as one of the 10 types of sialic acids, essential for in vivo biopotency of FSH in primates.

In the mid-1960s, Moudgal's group made the significant observation that neutralization of circulatory luteinizing hormone (LH) results in blockade of reproductive processes like ovulation, implantation, gestational progress, etc. This was a major breakthrough in reproductive biology. It not only provided a vastly superior substitute technique to hypophysectomy for establishing the role of a hormone in any physiological process, but it also provided an opportunity for Moudgal to use such characterized antibodies as fine probes to study hormone action in great detail. The significance of these observations, made in rodents, to the development of immunocontraceptive technology applicable to humans was not missed. His publication "Can hormone antibodies be used as a tool in fertility control?" (Moudgal et al. 1974a) formed the basis for the development of an immunocontraceptive approach for regulating fertility in females. Indeed, Prof RO Greep of Harvard University, Boston, USA, invited Moudgal to spend some time in his laboratory to extend these observations and, if possible, to extend the validity of these findings to New World monkeys and subhuman primates. Between 1969 and 1971 Moudgal supervised work of Greep's group at Harvard University, leading to more than dozen path-breaking papers on the role of LH in regulation of ovulation and regulation of corpus luteum in Macaca fascicularis. He also initiated work on LH receptors during his stay at Harvard University.

Moudgal's group had demonstrated the hormonal mechanism of ovarian quiescence during lactation in rodents and primates. For the first time, it was demonstrated that prolactin could mimic the action of suckling in inhibiting the action of LHRH on the pituitary provided minimal suckling stimulus is maintained. For example, in the lactating pregnant rat model while 8-pup-suckling intensity can block implantation, 2-pup-suckling intensity cannot. The administration of prolactin to the 2-pup suckling group could completely block LHRH action on release of gondadotrophins and initiation of implantation. This significant observation was published in Endocrinology, the mouthpiece of the American Endocrine Society. The parallel observations made in monkeys were published in Nature (London).

Moudgal's group demonstrated the degrees of coupling between hormone binding to receptors and response in terms of cAMP production and steroid output. Many groups all over the world were working on the quantitative relationships between receptor occupancy and proximal/distal responses.

A significant observation made by him was that immunoneutralization of circulating FSH in bonnet monkeys (Mecaca radiata) resulted in oligozoospermia and even azoospermia. He successfully demonstrated the need for FSH for initiation of spermatogenesis in non-human primates and humans. This led to his continued interest in developing a vaccine for the purposes of immunocontraception in the male human subjects. His interest in immunocontraception and the concerns expressed by educated society at large 
stimulated him to look for a male immunocontraceptive vaccine candidate. His own observations in rodents and bonnet monkeys (Macaca radiata) convinced him that FSH was the answer.

Extensive work was carried out to realize the potential of FSH as a male immunocontraceptive vaccine candidate. Good Laboratory Practices demanded that recombinant antigens be used. Based on detailed studies using Macaca radiate, which clearly established that FSH was a credible candidate male contraceptive vaccine, Phase I clinical studies were initiated and completed successfully. Further studies were stalled due to interference at the various scientific levels, resulting in the country losing the opportunity to develop a male contraceptive vaccine (Moudgal et al. 1997). Moudgal's interest in immunocontraception enabled him to look at other related reproductive phenomena like regulation of follicular maturation and atresia in the female, spermatogenesis in the male, the role of oestrogen in spermatogenesis, primate reproduction and lactational amenorrhea. In 1973 Moudgal organized an international symposium to take stock of the field of gonadotropins and to resolve some problems in their structure, mechanism of action, and immunocontraceptive potential. The who's who of reproductive endocrinology in the world attended this symposium and shared their data.

During his long career spanning more than 40 years, Moudgal made seminal contributions: he was the first one to initiate research in the areas of endocrine biochemistry, reproductive physiology, and primate biology by using immunological methods. He conducted systematic studies using highly characterized antibodies to gonadotrophins to block their action and demonstrated the critical role of these hormones in follicular maturation and implantation using rodents and non-human primates as models. His pioneering work using antibodies to luteinizing hormone formed the basis of further studies on immunological approaches to human contraception.

Moudgal's group published over 250 papers and reviews and numerous chapters in books. He has published in some of the most prestigious journals like Nature, Endocrinology, Biology of Reproduction, Current Opinion in Immunology, Biochemical Journal, Journal of Biological Chemistry, Journal of Reproduction and Fertility, Journal of Endocrinology, Fertility and Sterility, etc. Moudgal's laboratory was recognized as a ICMR Centre of Advanced Studies in Reproductive Endocrinology. Although he began his career in the Department of Biochemistry, the size of his group and productivity justified the creation of a separate Centre for Reproductive Biology and Molecular Endocrinology (CRBME), which later was upgraded as Department of Molecular Reproduction and Developmental Genetics (MRDG). He also established and ran the largest primate house in the country, the Primate Research Laboratory (PRL). This was one of the best in the world, housing at one time, more than 400 monkeys with pedigree and health records, and he published several papers using exclusively bonnet monkeys as models. Many veterinarians worked with Moudgal to obtain their doctorates.

He served as Editor of Journal of Bioscience during its inception and moulded its development. He was on the editorial board of Molecular and Cellular Endocrinology, a European journal. Moudgal mentored 18 doctoral students and 14 post-doctoral fellows. He was a member of the Society of Biological Chemists (India), and represented it in the Federation of Oceanian Biochemists as its Secretary-General. He was a member of the Endocrine Society (USA) and the Society for the study of Reproduction (USA). He was founder president of the Indian Society of Reproduction. He was an elected fellow of both the Indian Academy of Sciences, Bangalore, and the Indian National Science Academy, New Delhi. Moudgal received many awards, including the BC Guha Award (1975), SS Bhatnagar Award (1976), Sreenivasayya Memorial Award of SBC (I), Sanjay Gandhi Award for Science and Technology (1984) and the Yellapragada Subbarow Birth Centenary Lecture Award of INSA (1996). Moudgal was a Homi Bhabha Fellow (1978). He was the first Indian scientist to present his research work at the prestigious Laurentian Hormone Research Conference, Canada (Moudgal et al. 1974b).

Moudgal's standards were global and he was always the leading researcher in his field. His creative energy and passion for research was impressive and infectious. He was always enthusiastic and encouraging even when laboratory experiments were not going well. Every week during laboratory seminars he would come up with dozens of new ideas. He was a visionary and always the first one to get new equipment. His laboratory was one of the best equipped in the entire biology division. Moudgal was and will remain an inspiring leader in his commitment to science, experimental work and mentoring younger colleagues. He was peerless in choosing contemporary research problems and focusing on them within single-minded devotion. 


\section{References}

Moudgal NR, Rao AJ and Prahalada S 1974a Can hormone antibodies be used as a tool in fertility control? J. Reprod. Fert. Suppl. 21 105-123

Moudgal NR, Jagannadha Rao A, Maneckjee R, Muralidhar K, Mukku V and Sheela Rani CS 1974b Gonadotropins and their antibodies. Rec. Prog. Horm. Res. 30 47-77

Moudgal NR, Murthy GS, Prasanna Kumar KM, Martin F, Suresh R, Medhamurthy R, Patil S, Sehgal S and Saxena BN 1997 Responsiveness of human male volunteers to immunization with ovine follicle stimulating hormone vaccine: results of a pilot study. Hum. Reprod. 12 457-463

A Jagannadha Rao and N Appaji RaO Department of Biochemistry, Indian Institute of Science, Bangalore 560 012, India (Emails,ajrao@biochem.iisc.ernet.in,bcnar@biochem.iisc.ernet.in) 